\title{
Ensino de língua portuguesa com a mediação das tecnologias digitais em tempos de pandemia
}

\author{
Portuguese language teaching with mediation of digital technologies in \\ pandemic times
}

Raquel Mignoni de Oliveira

Mestra em Educação

Universidade de Caxias do Sul - UCS. Caxias do Sul, Rio Grande do Sul - Brasil. quelmig@yahoo.com.br

\author{
Ygor Corrêa \\ Doutor em Informática na Educação \\ Universidade de Caxias do Sul - UCS. \\ Caxias do Sul, Rio Grande do Sul - Brasil. \\ correaygorprof@gmail.com
}

Resumo: Este artigo apresenta uma pesquisa qualitativa exploratória, cujo objetivo é mostrar práticas educativas com uso de tecnologias digitais (TDs), de modo a compreender as potencialidades e as fragilidades do uso delas no Ensino Remoto Emergencial. Para isso, apresentase um relato de experiência sobre o uso de ferramentas digitais na disciplina de Língua Portuguesa para três turmas de $8^{\circ}$ ano, durante dois trimestres de 2020, do Ensino Fundamental, de uma escola da rede privada de ensino, situada na cidade de Caxias do Sul - RS, durante um período da pandemia de COVID-19. Neste horizonte, quatro ferramentas digitais foram utilizadas: (i) Publisher; (ii) Meme Generator-imgflip; (iii) Mentimeter e (iv) Quizlet. O estudo revelou que as TDs, enquanto mediadoras do conhecimento, apontam para mudanças significativas na postura do professor e dos alunos em relação aos processos de aprender e ensinar no ERE, tendo permitido identificar potencialidades e fragilidades, no que se refere ao uso das ferramentas tecnológicas digitais adotadas.

Palavras-chave: Educação. COVID-19. Tecnologias digitais. Ensino remoto emergencial.

Abstract: This article presents an exploratory qualitative research whose objective is to show educational practices using Digital Technologies (DTs), seeking to understand the potential and fragilities of their use in Emergency Remote Education. For this, an experience report on the use of digital tools in the discipline of Portuguese Language is presented for three classes of 8th grade, during two quarter of Elementary School of a private school, located in the city of Caxias do Sul RS, during a period of the COVID-19 pandemic. In this horizon, four digital tools were used: (i) Publisher, (ii) Meme Generator - imgflip; (iii) Mentimeter and (iv) Quizlet. The study revealed that DTs provide significant changes in the attitude of the teacher and the students about the processes of learning and teaching in the ERE as knowledge mediator, allowing to strengths and weaknesses, with regard to the use of technological tools adopted.

Keywords: Education. COVID-19. Digital technologies. Emergency remote education. 
OLIVEIRA, Raquel Mignoni de; CORRÊA, Ygor. Ensino de língua portuguesa das tecnologias digitais em tempos de pandemia

\section{Introdução}

A área da Educação, diante da pandemia de COVID-19 ${ }^{1}$, tem exigido que se tenha um olhar atento, de acolhimento e de renovação, frente aos processos de ensino e de aprendizagem, haja vista ser essencial desenvolver práticas educativas que contemplem as necessidades educacionais dos alunos. A partir da nova realidade de isolamento social, aulas síncronas e atividades assíncronas passaram a ser o novo real educacional, o que implica no uso da mediação por computadores ou dispositivos móveis, como tablets e smartphones, com contornos bem específicos, enquanto modalidade de ensino. Neste contexto, este artigo apresenta um relato de experiência (FORTUNATO, 2018) sobre o uso de ferramentas digitais para a produção e apresentação de atividades didáticas na disciplina de Língua Portuguesa (LP), durante os dois primeiros trimestres letivos do ano de 2020, conduzidos na modalidade de Ensino Remoto Emergencial (ERE), devido à pandemia de Coronavírus.

Desta forma, tem-se por expectativa que o leitor deste artigo possa ser levado à reflexão acerca da elaboração, da proposta e da realização de atividades na disciplina de LP, com vistas a evidenciar o modo como ferramentas digitais foram inseridas nas aulas ministradas no ERE e como essas podem auxiliar no ensino e aprendizagem dos estudantes, enquanto mediadoras, em uma perspectiva vygotskiana (VYGOTSKY, 1993), ao considerar suas especificidades tecnológicas.

Neste sentido, aporte teórico-epistemológico deste estudo está apoiado na proposta sociointeracionista vygotskiana (VYGOTSKY, 1993), que visa a fomentar a reflexão sobre a prática educativa docente, a qual demanda uma remodelação do papel do professor, da participação ativa dos alunos e suas famílias e do uso de Tecnologias Digitais (TDs). Este artigo, portanto, tem por objetivo mostrar práticas educativas com uso de TDs, buscando compreender as potencialidades e as fragilidades do uso dessas no ERE (WILLIAMSON; EYNON; POTTER, 2020; BEHAR, 2020; SANTANA; SALES, 2020), além de discorrer, inicialmente, a respeito da Educação em tempos de pandemia, a partir de autores como Nóvoa (2020), Honorato e Marcelino (2020) e Behar (2020).

Para tanto, este artigo, por meio de uma pesquisa qualitativa exploratória (SAMPIERI; COLLADO; LUCIO, 2013), dedica-se à apresentação um relato de experiência (FORTUNATO, 2018) sobre o uso de ferramentas digitais na disciplina de LP para turmas de $8^{\circ}$ ano (Anos Finais) do Ensino Fundamental de uma escola da rede privada de ensino, situada na cidade de Caxias do Sul, Rio Grande do Sul, Brasil, durante o período de pandemia de COVID-19. Neste horizonte, quatro ferramentas digitais foram utilizadas, a saber, (i) Publisher, (ii) Meme Generator- imgflip; (iii) Mentimeter e (iv) Quiz̨let para explorar, pedagogicamente, os conteúdos programáticos da disciplina 
OLIVEIRA, Raquel Mignoni de; CORRÊA, Ygor. Ensino de língua portuguesa das tecnologias digitais em tempos de pandemia

de LP. Após a apresentação do relato de experiência, são apresentadas considerações, a partir da literatura adotada neste estudo, de modo a ressaltar as possíveis potencialidades e fragilidades relacionadas ao uso de TDs na Educação.

\section{A educação frente à pandemia de COVID-19}

Os desafios impostos pela pandemia de Coronavírus fizeram com que gestores de escolas se empenhassem em promover o acesso à Educação, inserindo, sempre que possível, em ambientes virtuais de aprendizagem (AVAs), professores e alunos, a fim de dar continuidade ao ano letivo na modalidade remota (MATOS, 2020). Esse novo formato de ensino demandou uma nova postura de professores e de alunos, de maneira a amenizar os possíveis prejuízos, quanto às aulas, "os professores buscam fazer com que seus estudantes aprendam conteúdos considerados, socialmente, necessários, enquanto aguardam o retorno das aulas presenciais" (HONORATO; MARCELINO, 2020, p. 209).

Diante realidade mencionada, é importante avaliar as condições remotas de ensino e de aprendizagem, além do papel docente e discente, exigido pelo novo contexto educacional, para que a Educação chegue a todos os alunos. De acordo com Matos (2020), muitos estudantes, principalmente, pertencentes ao ensino público, não estão acompanhando as aulas, por não terem acesso a elas, devido à falta de equipamentos eletrônicos e à conexão com a Internet. O ensino em si está em colapso, segundo a United Nations Educational, Scientific and Culture Organization (UNESCO, 2020), muitas estão sendo as consequências do fechamento das escolas, assim as disparidades como: evasão escolar, desnutrição, lacunas nos cuidados infantis, dentre outros que já existiam e se acentuaram.

No entanto, para outros alunos, como os do ensino privado, as aulas remotas têm sido, notoriamente, uma opção para dar sequência aos estudos, enquanto prática temporária, uma vez que o ensino remoto acarreta implicações "importantes para o desenvolvimento do processo ensino-aprendizagem. Entende-se que a escola não existe sem professores, sem alunos, sem corpo pedagógico-administrativo e sem a família" (HONORATO; MARCELINO, 2020, p. 211). Desse modo, observa-se que o ERE, embora assegure uma continuidade escolar, ele não dá conta de todas as necessidades educacionais, que envolvem, acima de tudo, as relações interpessoais.

Além disso, é fundamental que se reflita sobre os métodos pedagógicos usados na promoção do ensino, bem como refletir acerca da mediação entre o que se ensina e como se ensina. Afinal, o objetivo do uso de ferramentas tecnológicas não é transpor conteúdo, mas contribuir para atividades criativas, colaborativas e autorais (SANTANA; SALES, 2020). Assim, entende-se que o 
OLIVEIRA, Raquel Mignoni de; CORRÊA, Ygor. Ensino de língua portuguesa das tecnologias digitais em tempos de pandemia

uso de plataformas digitais tem contribuído para o ensino, mas "os processos de ensinar e aprender não são tão simples de serem resolvidos apenas por recursos tecnológicos. Lidar com seres humanos é complexo, os ritmos, os tempos e os processos de aprendizagem são diferentes" (HONORATO; MARCELINO, 2020, p. 213). Desta forma, os professores têm que se adaptar às novas ferramentas digitais para cativar a atenção dos alunos e despertar o interesse deles, estimulando-os a serem ativos, diante do processo de aprendizagem.

Essa mudança na postura do aluno, que nem sempre acontece, faz com que ele seja capaz de ir em busca de respostas, a partir dos desafios lançados pelo professor, pois “[...] aprender é estar sempre na posição de "descobridor", tomando para si aquela curiosidade em aprender, por entender, por apropriar-se da cultura, que se modifica e que se apresenta agora" (FILHO, 2011, p. 57). Neste sentido, compreende-se que “[...] aprender é visar a uma autonomia e independência. Por isso, é fundamental que o aluno renuncie ao papel de receptor" (FILHO, 2011, p. 57). Entretanto, diante do contexto de pandemia de COVID-19 e do distanciamento social, a linguagem das tecnologias digitais no âmbito educacional tem sido um desafio para se pensar em práticas educacionais, para além do momento de aula (NÓVOA, 2020).

Já o professor, enquanto facilitador dos processos de ensino, pode encontrar nas tecnologias digitais um espaço para aulas mais criativas, incluindo novos espaços para que a aprendizagem ocorra. Movimento que demanda refletir e respeitar o aluno em sua individualidade, saindo da aula expositiva para desenvolver práticas colaborativas e significativas, nas quais os estudantes são inseridos em espaços de criação, de diálogo, de interação e de conhecimento (NÓVOA, 2020). Sabe-se que há restrições e potencialidades ao se trabalhar remotamente, diferente do ensino presencial, porém, é nessa perspectiva de conflito; e ao mesmo tempo dialógica, que se busca a reinvenção de padrões e a ressignificação da escola para a aprendizagem do aluno (SANTANA; SALES, 2020). Na próxima seção, discorre-se acerca do uso de tecnologias digitais na modalidade de ensino remoto.

O uso de tecnologias digitais como estratégia educacional no ensino remoto emergencial

No período de pandemia de COVID-19, o cenário escolar mudou, tendo em vista o fechamento das escolas por tempo indeterminado, o que gerou insegurança quanto à organização do ano letivo de 2020. Ao considerar o quadro de isolamento social, pânico e medo vivenciados, diariamente, muitos têm sido os desafios ao se pensar sobre a Educação, quando da adoção do Ensino Remoto Emergencial (ERE). Na área da Educação, o ERE foi definido por Behar (2020, online) como uma modalidade de ensino "que pressupõe o distanciamento geográfico de 
OLIVEIRA, Raquel Mignoni de; CORRÊA, Ygor. Ensino de língua portuguesa das tecnologias digitais em tempos de pandemia

professores e alunos e foi adotada de forma temporária nos diferentes níveis de ensino por instituições educacionais do mundo inteiro para que as atividades escolares não sejam interrompidas".

O ERE transpõe o ensino presencial físico para os contextos digitais, nesse sentido, professor e aluno estão conectados via dispositivos educacionais, seja por meio de webconferência ou videoaula, contemplando, na maior parte do tempo, o ensino voltado ao conteúdo, sendo "bidirecional", ou seja, de um para muitos (MOREIRA; SCHLEMMER, 2020). Essas características o diferenciam do modelo de Educação a Distância (EaD), tendo em vista as dimensões políticas, sociais e educacionais (BEHAR, 2020). Contudo, ao observar tal cenário, questiona-se: como as tecnologias digitais podem servir de mediadoras para o ensino? Nesse horizonte, a utilização das Tecnologias Digitais (TDs) ganhou espaço, exigindo que professores e alunos se adaptassem aos modos síncronos de ensinar e de aprender, com vistas a ressignificar seus processos pedagógicos. Infere-se que AVAs, aplicativos e softwares podem contribuir para que as salas de aula se pareçam mais com ambientes do mundo real e, assim, se consiga preparar melhor os alunos para fazerem parte de uma população cada vez mais ativa, conectada e globalmente competitiva. Há muitas ferramentas tecnológicas que podem ajudar os professores a simplificar os processos diários e ampliar o ensejo ao incorporar o raciocínio crítico, a comunicação, a colaboração e a criatividade à aprendizagem dos alunos, pois “a tecnologia não é tão somente um potente recurso para o aprendizado, mas também uma ferramenta cada vez mais relevante para a vida” (PEDRÓ, 2016, p. 11).

Contudo, as TDs tornaram-se a própria sala de aula, favorecendo a aprendizagem dos alunos e servindo como mediadora do processo de aprender. De modo geral, mediar pressupõe ações que acontecem por meio da colaboração entre as partes, ou seja, da interação entre os sujeitos e da utilização de instrumentos que contribuam para esse processo. Na perspectiva de Vygotsky (1993), a mediação contribui para o desenvolvimento do pensamento, que vai do social (interpessoal) para o individual (intrapessoal), sendo que aprendizagem e desenvolvimento estão inter-relacionados. Neste tocante, a mediação mobiliza o aprender e este parte da colaboração para, posteriormente, se tornar um processo individual. Desta forma, as TDs são o elo que proporciona aos alunos e aos professores, remotamente, a possibilidade de aprenderem conjuntamente. Assim, acredita-se que as TDs são capazes de provocar mudanças, mas, para isso, mais do que integrá-las à aprendizagem é necessário percebê-las e usá-las "numa perspectiva mais global e capaz de se adaptar à mudança contínua numa sociedade da informação e do conhecimento.” (GONÇALVES; 
OLIVEIRA, Raquel Mignoni de; CORRÊA, Ygor. Ensino de língua portuguesa das tecnologias digitais em tempos de pandemia

MOREIRA \& CORREA, 2019, p. 02). Para isso é preciso que se tenha condições apropriadas para lidar os desafios tecnológicos que surgem a cada dia, a fim de suprir uma Educação presencial.

Ao considerar esse panorama, é importante que haja diálogo e reflexão entre professores e alunos, quanto ao uso das tecnologias digitais para o gerenciamento do tempo, do conteúdo e do tipo de atividade a ser explorada no ERE. Além disso, prestar mais atenção no processo, do que no produto, facilita a integração do seu uso, modifica a relação do professor-aluno, o que proporciona um engajamento maior na dinâmica da aula, o estudante passa a ter mais autonomia, sendo visto como produtor do conhecimento e não mero receptor dele. Os alunos, por sua vez, podem colaborar em rede, favorecendo a autonomia, bem como facilitando a personalização do ensino (BACICH; MORAN, 2018).

As TDs, sem dúvida, estimulam a criatividade dos alunos e permitem a ressignificação da escola, no entanto, os professores têm que estar habilitados, bem como conhecer as ferramentas e o potencial delas, assim como o aluno, pois as TDs, "por si só, não serão suficientes, a menos que sejam acompanhadas de estratégias de planejamento, construção e exploração eficientes dos conteúdos” (GONÇALVES; MOREIRA; CORRÊA, 2019, p. 01). A Educação acontece pela conexão: dos pares com a rede e com o mundo (BACICH; MORAN, 2018).

Rede privada de ensino: a disciplina de língua portuguesa no ensino remoto emergencial

Diante do referido contexto de Educação em meio à pandemia, as redes de ensino, aderiram ao ERE como estratégias de enfrentamento ao distanciamento social, quando do fechamento de suas unidades escolares. A rede de ensino privada de Educação Básica investigada neste estudo, a qual compreende os níveis fundamental e médio, conforme a LDB (BRASIL, 1996b), está presente em 80 países, no Brasil, possui 45 unidades escolares. A unidade situada na serra gaúcha conta com, aproximadamente, 190 professores e atende mais de 1700 alunos matriculados entre o ensino infantil; o ensino fundamental e o ensino médio.

A rede de ensino descrita, mesmo em meio ao confinamento, que tem feito parte do cotidiano de alunos e professores, buscou as TDs, a fim de dar continuidade às aulas, ainda que ministradas de forma remota (WILLIAMSON; EYNON; POTTER, 2020). A partir deste cenário de incertezas e grandes mudanças, os professores procuram se reinventar para poder ensinar em meio à pandemia. Desta forma, assim como as demais disciplinas que compõem a grade curricular do oitavo ano do ensino fundamental, a disciplina de LP vem sendo ministrada na modalidade de ERE. A LP está inserida na área de Linguagens, conforme a Base Nacional Comum Curricular BNCC (BRASIL, 2017a) e fomenta a realização de práticas sociais mediadas por diferentes 
OLIVEIRA, Raquel Mignoni de; CORRÊA, Ygor. Ensino de língua portuguesa das tecnologias digitais em tempos de pandemia

linguagens (oral, corporal, escrita e visual), aprofundando a capacidade de reflexão crítica dos estudantes e de estimular a partilha de informações, experiências e ideias em diferentes contextos (BRASIL, 2017a).

Ao ensinar a LP, busca-se, a partir do texto, abordar perspectivas enunciativo-discursivas, - embora a BNCC não explicite em qual base teórica se ancora, ela parte de uma abordagem dialógica e apresenta "conceitos como interação verbal, dialogismo, gêneros do discurso e cronotopo" que abarcam-se de forma significativa no referido documento normativo (DANTAS; SANTOS, 2020) - de modo a relacioná-la a seus contextos de produção e de desenvolvimento de habilidades, no que se refere ao uso da linguagem, contemplando a cultura digital (BRASIL, 2017a).

Tendo em vista a compreensão "das práticas de linguagem relacionadas à interação e à autoria (individual ou coletiva) do texto escrito, oral e multissemiótico, com diferentes finalidades e projetos enunciativos" (BRASIL, 2017a, p. 76), é que a BNCC orienta abordar a produção textual. Dentre os conteúdos programáticos previstos para o oitavo ano, conforme a Matriz Curricular da escola tem-se: frase, oração; período; complementos verbais; período simples e composto; formas nominais; oração coordenada e subordinada. Já quanto ao que corresponde aos gêneros textuais, tem-se: crônica; esquete; tirinha; charge; memes; reportagem, notícia; biografia; autobiografia; artigo de opinião; texto de divulgação científica; textos publicitários. Contudo, neste relato, o recorte recai sobre (i) produção textual com ênfase no gênero informativo e meme e (ii) aspectos da gramática Normativa, com ênfase nas formas nominais e oração coordenada. A seguir, apresenta-se a metodologia de pesquisa deste estudo.

\section{Metodologia}

Esta é uma pesquisa qualitativa exploratória (SAMPIERI; COLLADO; LUCIO, 2013) que apresenta um relato de experiência sobre o uso de TDs como ferramentas digitais na disciplina de Língua Portuguesa (LP), durante o período de pandemia de COVID-19, para três turmas de $8^{\circ}$ ano dos anos finais do Ensino Fundamental de uma escola da rede privada na cidade de Caxias do Sul no Rio Grande do Sul (RS), cujas turmas possuem em média 32 alunos com faixa etária de 13 a 14 anos, totalizando 88 alunos. A pesquisa exploratória configura-se como relato de experiência, enquanto método de pesquisa, ao discriminar o contexto investigado e qualificar as ações nele observadas, a fim de viabilizar um resultado acerca da experiência em que o pesquisador é o próprio participante (FORTUNATO, 2018). Desse modo, o relato de experiência pode oportunizar a outros pesquisadores a reflexão acerca de circunstâncias análogas ao que está descrito. Ainda para 
Fortunato (2018, p. 45) um relato de experiência deve apresentar "nove elementos para a condução de uma pesquisa educacional" sendo esses:
(1) antecedentes;
(2) local;
(3) motivo;
(4) agente(s);
(5) envolvidos;
(6) epistemologia para ação;
(7) planejamento;
(8) execução; e
(9) análise por uma lente teórica.

Para tanto, objetiva-se evidenciar como práticas educativas com uso de TDs, podem apresentar potencialidades e fragilidades, quando inseridas no ERE. Para tanto, a professora apresentou propostas de atividades relacionadas ao ensino da Língua portuguesa aos alunos de $8^{\circ}$ ano - anos finais do Ensino Fundamental, a saber, a primeira, voltada à produção de texto, e, a segunda, relacionada à gramática, utilizando quatro ferramentas tecnológicas digitais como mediadoras, sendo elas: (I) Publisher, (II) Meme Generator imgflip; (III) Mentimeter e (IV) Quizlet. Na próxima seção são apresentadas as ferramentas tecnológicas e a descrição da utilização delas.

\section{Ferramentas tecnológicas digitais no ensino de língua portuguesa}

Esta seção destina-se a descrever e a refletir, com base em um relato de experiência (FORTUNATO, 2018), a prática docente de condução de 20h aulas da disciplina de LP na modalidade de ERE para três turmas de oitavo ano. $O$ relato de experiência volta-se, especificamente, para a reflexão acerca do uso de 04 ferramentas digitais, quando da realização das aulas de Língua Portuguesa, mediadas por aparato tecnológico (computador desktop, tablet ou smartphone) e conexão com a Internet, na modalidade de ERE, enquanto condição temporária para a continuidade das aulas que aconteciam de modo presencial (BEHAR, 2020).

No que concerne às aulas de Língua Portuguesa, a seguir, apresenta-se as atividades realizadas acerca de dois conteúdos programáticos, a saber, o primeiro, (a) produção textual, voltada aos gêneros textuais, Texto Jornalístico (texto informativo) e Meme (linguagem verbal e humor); e, o segundo, (b) gramática, em relação às formas nominais (infinitivo, gerúndio e particípio) e orações coordenadas (sindéticas e assindéticas). Para ministrar os dois conteúdos 


\section{Dialogia}

OLIVEIRA, Raquel Mignoni de; CORRÊA, Ygor. Ensino de língua portuguesa das tecnologias digitais em tempos de pandemia

programáticos mencionados foram eleitas ferramentas tecnológicas, que pudessem auxiliar na elaboração, na proposta e na realização das aulas na modalidade ERE.

Frente à nova realidade de isolamento social, tornar as aulas síncronas e as atividades assíncronas instigantes e dinâmicas foi o desafio central enfrentado, com vistas a tornar as aulas interativas e, também, acompanhar o engajamento dos estudantes, estimulando-os à aprendizagem de modo mais autônomo e com um olhar crítico para suas produções em contexto de ERE, mediado por aparato computacional (BNCC, 2017a). Quanto às atividades didáticas propostas acerca da (a) produção textual, voltada aos gêneros textuais, no Quadro 1, apresenta-se um panorama composto pelo (I) tema; (II) conteúdo programático, previsto na BNCC (BRASIL, 2017a); (III) a atividade elaborada; (IV) a ferramenta tecnológica (software); e (V) editoração.

Cabe ressaltar que, segundo a BNCC (BRASIL, 2017a) os gênero textuais exploradas no item (a), os gêneros jornalístico e meme, têm por finalidade desenvolver competências e habilidades como: refletir sobre os diferentes contextos e situações sociais de produção, bem como o meio analógico ou digital em que circulam; estabelecer relações entre as partes do texto, considerando o estilo do gênero e a construção composicional dele; selecionar informações relevantes e confiáveis; utilizar de maneira adequada os conhecimentos dos aspectos notacionais; desenvolver estratégias de revisão e edição, explorando os recursos multimídia disponíveis.

Quadro 1 - Produção textual a partir do uso de ferramentas digitais

\begin{tabular}{|c|c|c|}
\hline Tema & Gênero Textual Jornalístico & Gênero Textual Meme \\
\hline Conteúdo Programático & Texto informativo & $\begin{array}{l}\text { Humor } \\
\text { Linguagem verbal e não-verbal }\end{array}$ \\
\hline Atividade & $\begin{array}{l}\text { Criação de capa de jornal bilíngue - } \\
\text { em português e em inglês. }\end{array}$ & Produção de meme \\
\hline Software & Publisher ${ }^{2}$ & imgflip - meme generator ${ }^{3}$ \\
\hline Editoração & $\begin{array}{l}\text { Template de capa de jornal, com } \\
\text { espaços destinados ao texto } \\
\text { formato de parágrafos com } \\
\text { possibilidade de uso de imagem }\end{array}$ & $\begin{array}{l}\text { Template de meme com espaço } \\
\text { destinado à inserção de imagem e } \\
\text { de texto }\end{array}$ \\
\hline Tempo de planejamento & 6 horas & 4 horas \\
\hline Tempo de desenvolvimento & 6 horas-aula & 3 horas-aula \\
\hline
\end{tabular}

Fonte: Elaborado pelos autores. 2020.

Em relação ao item (a), quanto à abordagem da primeira atividade, voltada ao Gênero Textual Jornalístico, foram utilizadas algumas ferramentas tecnológicas digitais específicas, como o Publisher e Imgflip - memes generator para atingir o objetivo pedagógico previsto. 
A primeira tarefa consistiu em criar uma capa de jornal bilíngue. Primeiramente, foi realizada uma aula bilíngue, Língua portuguesa e Língua inglesa, mostrando os elementos da capa de um jornal e enfatizando suas funções, no que diz respeito ao objetivo de cada um. Destacou-se ainda a importância do veículo (jornal) e do gênero jornalístico para conhecer as diferentes realidades de determinadas regiões geográficas. Além disso, buscou-se enfatizar a importância e relevância da confiabilidade dos fatos noticiados pelo jornal. Posteriormente, a essa contextualização, foram estudados os gêneros notícia e reportagem, bem como os elementos que os compõem. Para finalizar, os alunos foram convidados a criarem sua própria capa de jornal, com o objetivo de materializar o que aprenderam sobre o gênero jornalístico, por meio do Microsoft Publisher. Este programa faz parte do pacote da Microsoft Office e é usado para diagramação eletrônica, como elaboração de layouts com textos, gráficos, fotografias e outros elementos. Ao término, algumas capas de jornal foram publicadas nas redes sociais da escola.

A segunda atividade corresponde ao gênero Meme e foi criada a partir do programa Imgflipmeme generator, site que permite a criação de memes e apesar dele ter limitações no que se refere aos números de caracteres e de quantidade de imagens disponíveis conseguiu-se atender ao objetivo proposto pela disciplina de LP. O objetivo desta atividade foi mostrar aos alunos o uso da linguagem informal em textos escritos, bem como a relação entre as linguagens verbal e não verbal. Logo, os alunos foram desafiados a criarem memes, a partir de assuntos atuais. Posteriormente, foi realizado o festival de memes, em que todas as produções foram expostas para as turmas por meio de uma apresentação de slides e foi feita uma análise semiótica dessas produções por elas.

Pode-se perceber, até aqui, que as tecnologias digitais, além de mediarem as aulas, podem ser integradas à divulgação das ações realizadas pelos alunos para que se sintam estimulados a participarem e realizarem as atividades, permitindo que usem sua criatividade para explorar conteúdos. Cabe ressaltar, que os alunos tiveram autonomia para explorar outros recursos digitais na elaboração da atividade, se assim, se sentissem confortáveis em fazer, desde que apresentasse o conteúdo da atividade solicitada.

Na Figura 1, a Imagem 1 e a Imagem $2^{4}$ ilustram as atividades realizadas com os alunos. 


\section{Dialogia}

OLIVEIRA, Raquel Mignoni de; CORRÊA, Ygor. Ensino de língua portuguesa das tecnologias digitais em tempos de pandemia

Figura 1 - Atividades sobre os gêneros jornalístico e meme

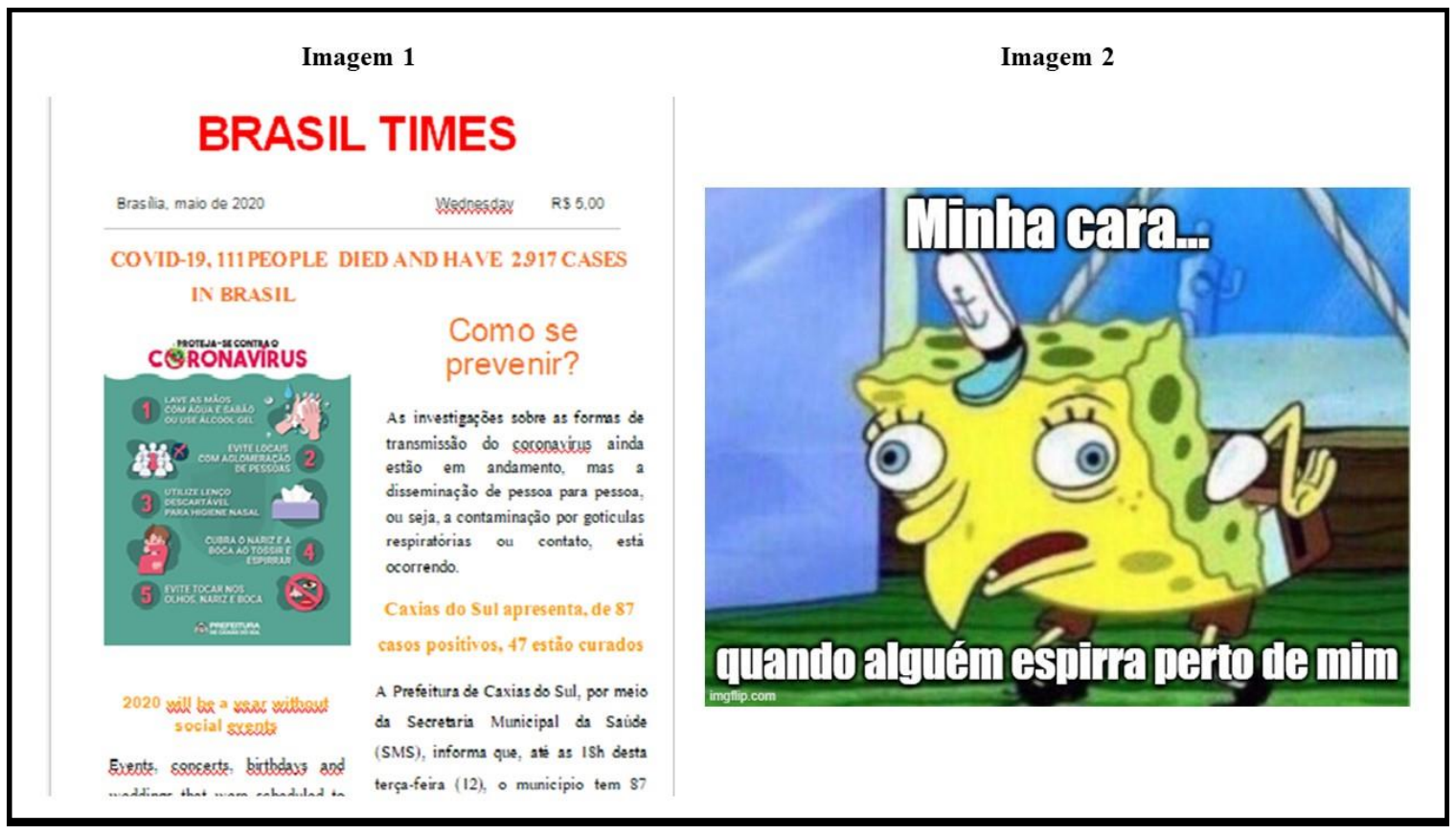

Fonte: Elaborado pelos autores. 2020.

Em ambas as atividades ilustradas, buscou-se avaliar se os alunos conseguiram refletir sobre diferentes contextos e situações sociais em que foram produzidos os textos, diferenciando a linguagem formal e informal, verbal e não verbal, bem como a importância delas na construção do sentido; se conseguiram estabelecer relações de intertextualidade para criá-los; se as informações selecionadas eram confiáveis e se possuíam um nível de aprofundamento adequado exigido pelo gênero; se foram estabelecidas relações entre as partes do texto, levando em conta a construção composicional e o estilo do gênero e, por fim, se utilizaram os aspectos notacionais da língua adequadamente (pontuação, concordâncias, ortografia, etc.). A avaliação foi realizada por meio da plataforma Google Classroom e o feedback aconteceu em dois momentos: individual e coletivo. O feedback individual ocorreu por meio da mesma plataforma, com breves comentários sobre as competências e habilidades desenvolvidas e o que havia necessidade de retomar e reestruturar. Já o feedback coletivo foi feito junto ao grande grupo, mostrando exemplos corretos de aplicação da língua e estrutura textual.

Desse modo, o uso de tecnologias digitais como mediadoras do processo de aprender tem se mostrado muito eficaz na criação de momentos que estimulem a participação dos alunos. A participação do aluno, como sujeito ativo, é sempre muito importante para que signifique o que está sendo ensinado, dessa forma, as TDs permitem uma maior interação entre professor-aluno e aluno-aluno. Isso pode ser verificado nas propostas de atividades exibidas no quadro 2 , com as 
OLIVEIRA, Raquel Mignoni de; CORRÊA, Ygor. Ensino de língua portuguesa das tecnologias digitais em tempos de pandemia

principais ferramentas digitais utilizadas no ensino de LP no que diz respeito à gramática, abordando dois tópicos: formas nominais e oração coordenada. Para esses conteúdos traz-se como competência e habilidade a serem desenvolvidas, a partir da BNCC (BRASIL, 2017a), (i) reconhecer as formas nominais; (ii) identificar agrupamento de orações em períodos, (iv)diferenciando coordenação de subordinação.

Quadro 2 - Ensino de gramático a partir do uso de ferramentas digitais

\begin{tabular}{|c|c|c|}
\hline Tema & Formas nominais & Oração coordenada \\
\hline Conteúdo Programático & Infinitivo, gerúndio e particípio. & Sindéticas e assindéticas \\
\hline Atividade & $\begin{array}{l}\text { Produção de uma nuvem de } \\
\text { palavras coletiva e realização de um } \\
\text { quis. }\end{array}$ & Quiz de fixação de conceitos \\
\hline Software & Mentimenter $^{5}$ & Quizlet $^{6}$ \\
\hline Editoração & $\begin{array}{l}\text { Programa online que permite a } \\
\text { criação }\end{array}$ & $\begin{array}{l}\text { Aplicativo que permite preparar } \\
\text { flashcards e outras atividades } \\
\text { interativas de revisão de conteúdos }\end{array}$ \\
\hline Tempo de planejamento & 4 horas & 2 horas \\
\hline Tempo de desenvolvimento & 2 horas-aula & 1 hora-aula \\
\hline
\end{tabular}

Fonte: Elaborado pelos autores. 2020.

Para explorar a gramática, partiu-se da leitura e da interpretação de um texto, buscando compreender a importância do estudo gramatical para a escrita e para o entendimento. Posteriormente, a esses movimentos, foram necessárias atividades que ajudassem os alunos a compreenderem os conteúdos estudados. Dessa forma, aqui, serão apresentadas duas atividades com a mediação das TDs, que contribuíram para a fixação desses conteúdos. Na primeira tarefa, o recurso Mentimeter foi utilizado para criar uma nuvem de palavras, a fim de sondar o conhecimento prévio dos alunos, em relação ao conteúdo (formas nominais) e, além disso, estimular a participação deles em tempo real, já que no ERE, por vezes, não se sabe se ele está presente de fato. Esse mesmo recurso serviu para verificar se os alunos compreenderam os conceitos, realizado na mesma plataforma, mas, agora, em formato de qui . O Mentimeter é uma ferramenta para ser usada online, que permite realizar atividades interativas com os participantes, por exemplo: nuvem de palavras; ranqueamento; perguntas abertas; perguntas com múltipla escolha, tópicos, também é possível criar quizzes de competição. É o tipo de ferramenta que envolve o estudante através da interatividade e ativa a curiosidade dos participantes; encoraja o educando a participar sem medo de julgamentos; coloca o aluno em posições mais ativas e reflexivas. É um ótimo recurso para ser usado em 
avaliações diagnósticas, como já apresentado aqui. No entanto, a versão gratuita é limitada quanto ao número de atividades que pode ser elaborada, por isso o professor deve estar atento quanto ao objetivo da aula e a escolha da ferramenta adequada.

A outra atividade (F2) contempla o conteúdo orações coordenadas, usou-se como recurso de interação o Quizlet. Por meio dessa ferramenta os alunos puderam, nos momentos offline, revisar os conceitos por meio de jogos (competindo com os colegas e os desafiando), testes e com o uso de flashcards. O Quizlet é uma ferramenta que permite a criação de listas de estudo sobre qualquer conteúdo. Através dela é possível aprender brincando com flash cards, jogos e testes. Esse recurso é interessante, pois não precisa estar conectado à internet e possui listas prontas ou podem ser criadas pelo professor ou pelo próprio aluno. 
OLIVEIRA, Raquel Mignoni de; CORRÊA, Ygor. Ensino de língua portuguesa das tecnologias digitais em tempos de pandemia

Figura 2 - Atividades sobre gramática: formas nominais e oração coordenada

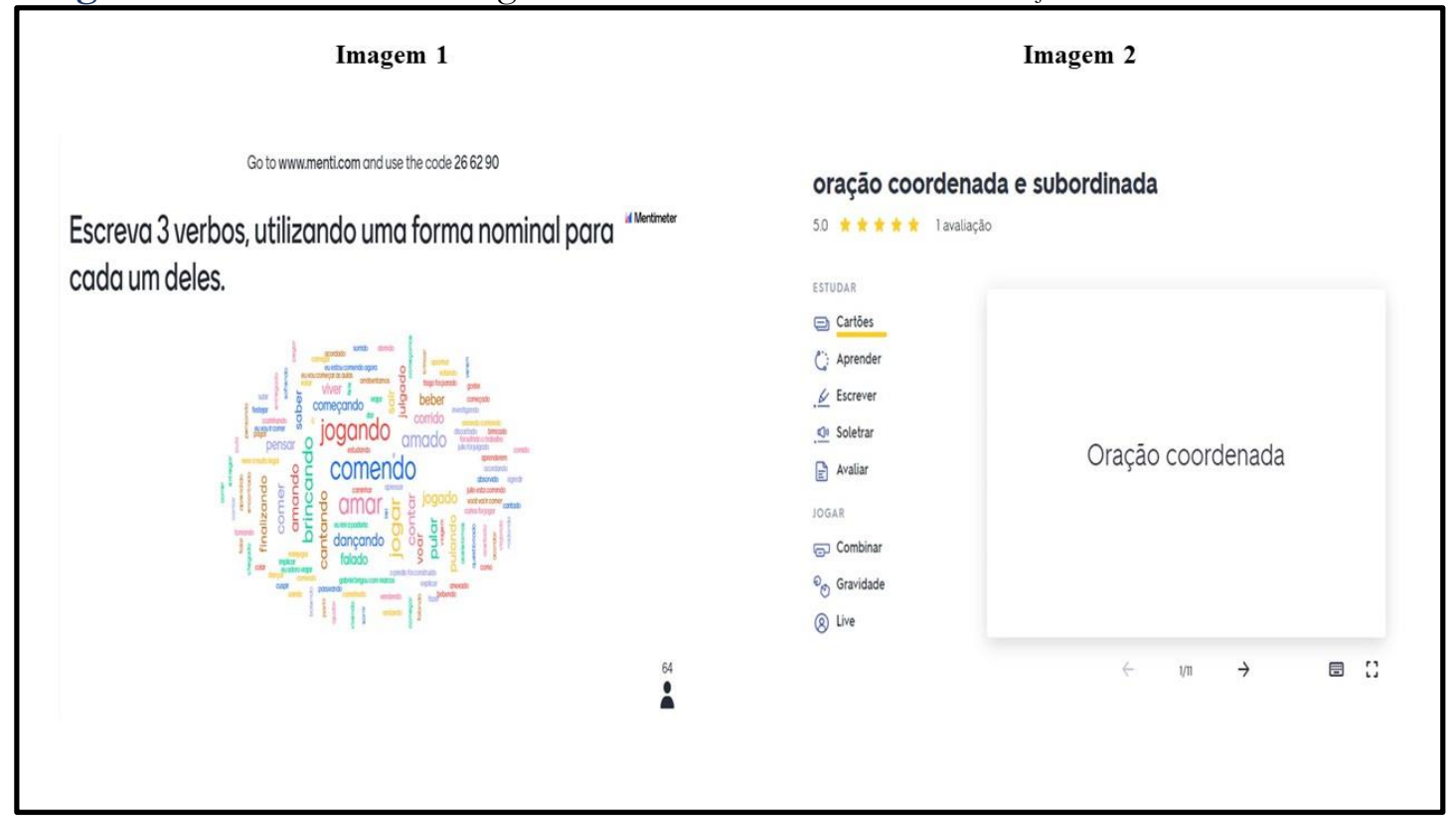

Fonte: Elaborado pelos autores. 2020.

Esses recursos são importantes para sondagens e testes diagnósticos. No caso do Mentimenter, é possível ver em tempo real as respostas dos alunos, mas sem identificá-los, podendo ser dado o feedback ao mesmo tempo em que a atividade acontece, buscando explicar o conteúdo, a partir do conhecimento deles. No caso de uso de quir, essa ferramenta permite que o professor faça download de um relatório que mostra o percentual de acertos e erros de cada turma, podendo ser utilizado para retomar com os alunos conceitos que ainda não estão consolidados. Já no Quizlet, isso não é possível, já que sua interação é offline. Nesse sentido, o feedback é feito pelo próprio aplicativo, que vai pontuando para o aluno o que já está consolidado e o que está em progresso. O que está em progresso é o que ainda precisa ser revisto. Vale lembrar, que todas as ferramentas aqui mencionadas são gratuitas, mas possuem versões pagas que permitem um uso mais amplo de suas funções.

Em relação ao uso das ferramentas aqui referidas, sempre se promoveu momentos de familiarização com o objetivo de utilização de cada ferramenta, assim como, juntamente, com a professora, os alunos foram expostos a uma breve instrumentalização acerca das funcionalidades de cada ferramenta tecnológica digital. Cabe salientar que, dependendo do aparato tecnológico do aluno, computador desktop, tablet, notebook ou uso de dispositivos móveis do tipo smartphone e Iphone, os alunos não precisavam, obrigatoriamente, utilizar os recursos apresentados pela professora, posto que eles poderiam fazer uso de recursos digitais outros que permitissem realizar a produção da tarefa solicitada. Em geral, o aparato tecnológico utilizado pelos alunos foi o computador do tipo desktop ou notebook, assim como, em alguns casos o uso de dispositivos móveis do tipo 
OLIVEIRA, Raquel Mignoni de; CORRÊA, Ygor. Ensino de língua portuguesa das tecnologias digitais em tempos de pandemia

smartphone e tablet. Na próxima seção são apresentas algumas considerações sobre a experiência aqui relatada.

\section{Considerações finais}

O ensino mediado por tecnologias digitais (TDs) no ERE, diante deste contexto de pandemia de COVID-19, tem despertado inúmeros desafios, no que corresponde ao ensino e a aprendizagem. É incontrovertível que professores e alunos tiveram que se adaptar a essa nova realidade de aulas online e tiveram que redimensionar suas práticas educativas.

Assim, neste artigo, discutiu-se sobre as práticas pedagógicas desenvolvidas na disciplina de LP na Educação básica de uma rede privada, por meio de um relato de experiência, o qual mostrou mudanças significativas na postura do professor e do aluno em relação aos processos de aprender e ensinar no ERE, haja vista o objetivo da aula, o conteúdo a ser explorado e as ferramentas que fornecem o suporte necessário para que fosse possível desenvolver a prática educativa. Entretanto, ao observar o uso das TDs no ensino, verificou-se algumas potencialidades, como: (1) ter objetivos claros ao utilizar uma ferramenta tecnológica digital; (2) conhecer e dominar o letramento sobre tal instrumento para poder auxiliar os alunos na hora da tarefa e atingir o objetivo inicial da aula; (3) engajar os alunos às tarefas, desenvolvendo um papel mais ativo e significativo; (4) dar feedback em todas as atividades. Esses quatro elementos foram fundamentais para se trabalhar com as TDs.

Contudo, no ensino online, constatou-se também algumas fragilidades: (1) não saber exatamente quem realmente está acompanhando a aula ou só deixou o computador ligado. Considerando esse fato, acredita-se que as TDs têm potencial para ressignificar as práticas pedagógicas, buscando a interação do aluno, a fim de que ele participe, mostrando-se como sujeito ativo nos processos educativos. Além disso, (2) as ferramentas digitais na versão gratuita, geralmente, possuem limitações de uso, como espaços de armazenamento e número de atividades que podem ser criadas, o que, por vezes, limita o trabalho do professor. Neste sentido, a busca por novas ferramentas é essencial, pois, saber as potencialidades e as fragilidades de cada recurso a ser utilizado faz com que o professor consiga criar estratégias para melhor desenvolver sua aula.

Pode-se dizer que a pandemia desvelou desafios e tensões, mas tem permitido identificar os pontos positivos e negativos na Educação, bem como desenvolver ações educacionais e estratégias de transformação no campo educacional, as quais possuem potencial para se tornarem permanentes as atividades letivas retornarem presencial ou semi-presencialmente. Contudo, o estudo revelou que as TDs, enquanto mediadoras do conhecimento, contribuem para a promoção 


\section{Dialogia}

OLIVEIRA, Raquel Mignoni de; CORRÊA, Ygor. Ensino de língua portuguesa das tecnologias digitais em tempos de pandemia

do ensino, favorecendo aulas mais interativas e colaborativas, mesmo diante do ERE. Assim, aqui ficam algumas memórias para se resgatar e registrar quanto aos desafios vivenciados nesse processo de transformação que tem ocorrido em todo o mundo.

1 “COVID-19 é causada pelo agente etiológico nomeado SARS-CoV-2, a qual surgiu, inicialmente, na China, em novembro de 2019 e se espalhou pelo país e pelo mundo”. (CASTAMAN; RODRIGUES, 2020, p. 03).

2 Programa do pacote Microsoft Office.

3 Disponível em: https://imgflip.com/memegenerator Acesso em: 14 ago. de 2020.

4 Essas imagens foram elaboradas pela professora como forma de ilustrar atividades que foram desenvolvidas juntamente aos alunos com o uso das ferramentas digitais adotadas quanto à produção de textos, gêneros texto jornalístico e memes.

5 Disponível em: https://www.mentimeter.com. Acesso em set. 2020.

6 Disponível em: https://quizlet.com. Acesso em set. 2020.

\section{Referências}

BACICH L.; MORAN J. Metodologias Ativas para uma Educação Inovadora: Uma Abordagem Teórico-Prática. Porto Alegre: Penso, 2018. e-Pub.

BEHAR, P. A. O Ensino Remoto Emergencial e a Educação a Distância. Jornal da Universidade (UFRGS). Disponível em: https://www.ufrgs.br/jornal/o-ensino-remoto-emergencial-e-aeducacao-a-distancia/. Acesso em: set 2020.

BRASIL. Base Nacional Comum Curricular: Educação Infantil e Ensino Fundamental. Brasília: MEC/Secretaria de Educação Básica, 2017a.

BRASIL. Lei de Diretrizes e Bases da Educação Nacional, LDB. Lei 9394/1996. 2016b. Disponível em: axias.rs.gov.br. Acesso em set. 2020.

CASTAMAN, A. S.; RODRIGUES, R. A. Educação a Distância na crise COVID - 19: um relato de experiência. Research, Society and Development, v. 9, n. 6, e180963699, 2020.

DANTAS, W.; SANTOS, E. C. As ideias linguísticas do círculo de Bakhtin na Base Nacional Comum Curricular (BNCC). Macabéa - Revista Eletrônica do Netlli, v.9, n. 3, 2020.

FILHO, A. P.. Educação a distância: uma abordagem metodológica e didática a partir dos ambientes virtuais. Educ. rev., v. 27, n.2. Belo Horizonte, 2011.

FORTUNATO, I.. O relato de experiência como método de pesquisa educacional. In: Ivan Fortunato; Alexandre Shigunov Neto. (Org.). Método(s) de Pesquisa em Educação. Edições Hipótese, São Paulo, v. 1, p. 37-50, 2018.

GONÇALVES, V.; MOREIRA, A.; CORREA, Y. Educação e tecnologias na sociedade digital,. Portugal, Whitebooks. 2019.

HONORATO, H. G.; MARCELINO, A. C. K.. A arte de ensinar e a pandemia covid-19: a visão dos professores. rede - Revista Diálogos em Educação, v. 1, n. 1, janeiro-junho, 2020. 


\section{Dialogia}

OLIVEIRA, Raquel Mignoni de; CORRÊA, Ygor. Ensino de língua portuguesa das tecnologias digitais em tempos de pandemia

MATOS, Eduardo. Um mês depois, cerca de $40 \%$ dos alunos da rede estadual seguem fora do sistema de aulas online. Disponível em: https://cutt.ly/kf3IspB. Acesso em: jul. 2020.

MOREIRA, J. A.; SCHLEMMER, E. Por um novo conceito e paradigma de educação digital onlife. Revista UFG, v. 20, 2020.

NÓVOA. A. Formação de professores em tempo de pandemia. Youtube. Jun. 2020. Disponível em: https://www.youtube.com/watch?v=ef3YQcbERiM. Acesso em: jun. 2020.

PEDRÓ, F. A tecnologia e a transformação da educação. Documento básico. Tradução: Maria Alicia Manzone Rossi. Fundação Santillana. 2016.

SAMPIERI, R. H.; COLLADO, C. F.; LUCIO, M. B. Metodologia de pesquisa. 5. ed. Porto Alegre: Penso, 2013.

SANTANA, C. L. S.; SALES, K. M. B.. Aula em casa: educação, tecnologias digitais e pandemia covid-19. Revista Interfaces Cientificas. Aracaju, v.10, n.1, p. 75 - 92, 2020.

UNESCO. Consequências adversas do fechamento das escolas. 2020. Disponível em:https://pt.unesco.org/covid19/educationresponse/consequences. Acesso em ago. 2020.

VYGOTSKY, L.S. Pensamento e Linguagem. São Paulo: Martins Fontes, 1993.

WILLIAMSON, B.; EYNON, R.; POTTER, J. Pandemic politics, pedagogies and practices: digital technologies and distance education during the coronavirus emergency. Learning, Media and Technology, v. 45, n. 2, p. 107-114, 2020.

Recebido em: 30 set. 2020/ Aprovado em: 10 nov. 2020

\section{Cite como}

\section{(ABNT NBR 6023:2018)}

OLIVEIRA, Raquel Mignoni de; CORRÊA, Ygor. Ensino de língua portuguesa das tecnologias digitais em tempos de pandemia. Dialogia, São Paulo, n. 36, p. 252-268, set./dez. 2020. Disponível em: https://doi.org/10.5585/dialogia.n36.18336.

\section{American Psychological Association (APA)}

Oliveira, R. M., \& Corrêa, Y. (2020, set./dez.).Ensino de língua portuguesa com a mediação das tecnologias digitais em tempos de pandemia. Dialogia, São Paulo, 36, p. 252-268.

https://doi.org/10.5585/dialogia.n36.18336 